\title{
Intrauterine Neospora caninum inoculation of heifers and cows using contaminated semen with different numbers of tachyzoites
}

\author{
E. Serrano-Martínez ${ }^{\text {a }}$, I. Ferre ${ }^{\text {a }}$, K. Osoro ${ }^{\text {b }}$, G. Aduriz ${ }^{\text {c }}$, R.A. Mota ${ }^{\text {a }}$, \\ A. Martínez $^{\text {b }}$, I. del-Pozo ${ }^{\text {c }}$, C.O. Hidalgo ${ }^{\text {d }}$, L.M. Ortega-Mora ${ }^{\text {a,* }}$ \\ ${ }^{a}$ Departamento de Sanidad Animal, Facultad de Veterinaria, Universidad Complutense de Madrid, \\ Ciudad Universitaria s/n, E-28040 Madrid, Spain \\ ${ }^{\mathrm{b}}$ Área de Sistemas de Producción Animal, Servicio Regional de Investigación y Desarrollo Agroalimentario (SERIDA), \\ Consejería de Medio Rural y Pesca, Asturias, E-33300 Villaviciosa, Spain \\ ${ }^{\mathrm{c}}$ Departamento de Sanidad Animal, Instituto Vasco de Investigación y Desarrollo Agrario (NEIKER), \\ Berreaga 1, E-48160 Derio, Bizkaia, Spain \\ a Área de Selección y Reproducción Animal, Servicio Regional de Investigación y Desarrollo Agroalimentario (SERIDA), \\ Consejería de Medio Rural y Pesca, Asturias, E-33202 Gijón, Spain
}

Received 15 September 2006; received in revised form 13 October 2006; accepted 19 October 2006

\begin{abstract}
Objective: To investigate the potential of different Neospora caninum tachyzoite doses to infect heifers (experiment 1 ) and cows (experiment 2) when administered in utero by artificial insemination via contaminated semen.

Methods: In experiment 1 , five groups of 5, 7, 8, 9, and 5 cyclic heifers were hormonally synchronized and artificially inseminated with semen containing 0 (A, controls), $10^{2}(\mathrm{~B}), 5 \times 10^{3}(\mathrm{C}), 5 \times 10^{4}(\mathrm{D})$, and $5 \times 10^{5}(\mathrm{E})$ live $N$. caninum NC-1 isolate-tachyzoites, respectively. Experimental infection was followed for 100 days. Parasitaemia and specific serum IgG, and interferon-gamma (IFN$\gamma$ ) responses were studied. In experiment 2, four groups of 9, 10, 9, and 9 adult multiparous cows with confirmed infertility problems of diverse aethiology were hormonally synchronized and artificially inseminated with semen containing 0 (a, controls), $10^{2}$ (b), $5 \times 10^{3}(\mathrm{c})$, and $5 \times 10^{5}$ (d) live $N$. caninum NC-1 isolate-tachyzoites, respectively. Experimental infection was followed for 63 days. Parasitaemia and specific serum $\mathrm{IgG}$ responses were studied.

Results: In experiment 1, parasitaemia was detected in 1, 2, and 3 heifers from groups B, C, and D, respectively, between 9 and 23 days after insemination. Persistent specific serum antibody responses were detected in 2 and 3 heifers from groups D and E, respectively. Transient specific serum antibody responses were detected in 2,1 and 1 heifers from groups $\mathrm{C}, \mathrm{D}$, and $\mathrm{E}$, respectively. In addition, 1 heifer from group B showed a serum-specific antibody level higher than cut off value at 21 days post-insemination. Heifers seroconverted between 23 and 47 days after insemination. Specific IFN- $\gamma$ levels were detected in 1, 4, 6, and 3 heifers from groups B, C, D, and E, respectively, between 9 and 55 days after insemination. Pregnancy rate in the control group (60\%) was higher than those observed in inoculated heifers (0-42.9\%). Pregnancy rates in inoculated heifers were lower when the tachyzoite dose was increased (B 42.9\%, C 12.5\%, D 11.1\%, and E 0\%). In experiment 2, no Neospora DNA in blood nor specific serum IgG to $N$. caninum were detected in any of the cows studied, except in one cow inoculated with $5 \times 10^{5}$ tachyzoites (group d) which showed a relative index $\times 100$ (RIPC) values of 9.4, 18.9, and 18.1 at 42, 56, and 63 days after insemination, respectively.

Conclusions: This study provides evidence that the intrauterine infection via contaminated semen using $5 \times 10^{4}$ and $5 \times 10^{5}$ tachyzoites caused persistent serum-specific antibody responses in some heifers. On the basis of serological data, a dose-response
\end{abstract}

\footnotetext{
* Corresponding author. Tel.: +34 91 3944069; fax: +34 913943908

E-mail address: luis.ortega@vet.ucm.es (L.M. Ortega-Mora).
} 
effect was also observed. In addition, $N$. caninum would be a probable cause of early foetal death in inoculated heifers. In contrast, results obtained in a similar experiment with cows showing confirmed infertility indicate that higher doses, such as of $5 \times 10^{5}$ tachyzoites, were necessary to induce seroconversion in at least one animal.

(C) 2006 Elsevier Inc. All rights reserved.

Keywords: Neospora caninum; Intrauterine inoculation; Infectious dose; Transmission; Heifers; Cows; Semen

\section{Introduction}

Neospora caninum is a heteroxenous cyst-forming apicomplexan closely related to Toxoplasma gondii which has emerged as an important cause of reproductive failure in cattle worldwide [1]. Neosporosis in bovines is a common cause of abortion and congenitally infected calves, which may show neural signs after birth [2].

In the Neospora life cycle, dogs [3] and coyotes [4] are both intermediate and definitive hosts, and cattle and other mammals are natural intermediate hosts [1,2]. Cattle are generally infected prenatally by transplacental infection from persistently infected dams $[5,6]$. Other possible postnatal sources of vertical transmission, such as colostrum or milk, have not yet been confirmed in naturally-infected cattle [7]. Epidemiological evidence also suggests horizontal transmission [6,8]. Calves [9] and pregnant cows [10] can be experimentally infected by oral administration of Neospora oocyst shed by dogs, and the $N$. caninum life cycle has been reproduced by cyclical oral transmission between dogs and cattle [11]. In addition, a sylvatic transmission cycle of $N$. caninum between cervids (white-tailed deer) and canids (dogs, coyotes) has been demonstrated in North America [12].

Since $N$. caninum DNA was reported in fresh and frozen semen from naturally-infected bulls [13-15], the possibility of venereal transmission has been suggested in bovine neosporosis. Recently, the intrauterine inoculation of $10^{7} \mathrm{~N}$. caninum $\mathrm{NC}-1$ isolate-tachyzoites in cyclic heifers was reported [16]. In this study, the nine heifers inoculated reacted with seroconversion and a specific IFN- $\gamma$ response. Moreover, $N$. caninum DNA was demonstrated in the blood of all nine heifers and in brain, liver and uterine horn of several of them. However, the numbers of tachyzoites used to test the venereal route of infection could be higher than those previously found in semen of naturally-infected bulls [15].

The objective of the present paper was to investigate the potential of different $N$. caninum tachyzoite doses to infect heifers (experiment 1) and cows with confirmed infertility problems (experiment 2 ) when administered in utero by artificial insemination (AI) using experimentally-contaminated semen.

\section{Materials and methods}

\subsection{Animals}

\subsubsection{Heifers}

Thirty-four cyclic heifers of the Asturiana de los Valles breed, aged between 11.1 and 29.6 (median 17.2) months with live weights from 268 to 504 (median 349) $\mathrm{kg}$ were used for experiment 1 . Before starting experiment 1 , blood samples were taken from all 34 heifers and tested for evidence of exposure to bovine viral diarrhoea virus (BVDV), infectious bovine rhinotracheitis virus (IBRV), Leptospira hardjo and Brucella abortus (assays conducted by the Instituto Vasco de Investigación y Desarrollo Agrario, NEIKER, Derio, Spain). The heifers were negative for all four abortifacient agents. Heifers were also tested twice by ELISA (CIVTEST, Hipra Laboratories S.A., Girona, Spain) for evidence of $N$. caninum exposure, and were all found to be seronegative.

\subsubsection{Cows}

Thirty-seven adult multiparous cows of the Asturiana de los Valles breed, aged between 3 and 18 (median 10) years with live weights from 362 to 662 (mean 491) $\mathrm{kg}$, were used for experiment 2 . All cows had previously shown infertility problems of diverse aethiology such as polycystic ovary and chronic endometritis. The 37 cows were brucellosis-free and vaccinated against BVDV and IBR (CattleMaster, Pfizer Animal Health) and leptospirosis (Leptovoid, Schering-Plough). For evidence of $N$. caninum exposure, cows were tested twice by ELISA (CIVTEST) and all tested seronegative.

\subsection{Experimental designs}

\subsubsection{Experiment 1: intrauterine $N$. caninum inoculation of heifers using contaminated semen with different numbers of tachyzoites}

The 34 heifers were randomly allocated into five groups (A, B, C, D, and E) of 5, 7, 8, 9, and 5 animals, 
respectively. Each experimental group was kept in a different pen in the same holding barn for the duration of the experiment. The heifers were isolated from other livestock in SERIDA facilities (Finca "La Mata", Grado, Asturias; Servicio Regional de Investigación y Desarrollo Agroalimentario del Principado de Asturias, Spain), and were fed with straw and a commercial cattle concentrate. All 34 cyclic heifers were synchronized hormonally with two doses of a synthetic PGF2 $\alpha$ analogue given 11 days apart $(2 \mathrm{ml}$ i.m., Prosolvin, Intervet, Salamanca, Spain). Oestrus detection (day 0; 2.5 days after the second PGF $2 \alpha$ analogue administration, on average) was based on monitoring behavioral signs three times daily and serum progesterone levels. Heifers were artificially inseminated using standard techniques on the same day to produce synchronous pregnancies. Mixed semen from two bulls of the Asturiana de los Valles breed that did not show specific serum antibodies to $N$. caninum by repeated ELISA (CIVTEST) was used for AI. Group A was inseminated with semen not contaminated with $N$. caninum tachyzoites and acted as a non-infected control group. Heifers from groups B, C, D, and E were inseminated with semen contaminated with $10^{2}, 5 \times 10^{3}$, $5 \times 10^{4}$, and $5 \times 10^{5}$ live $N$. caninum NC-1 isolatetachyzoites, respectively. The experiment was conducted between June and September 2004. The heifers were monitored daily for 100 days post-insemination (pi). Rectal temperatures of all animals were recorded before insemination and daily thereafter. Animals with temperatures above $39.5^{\circ} \mathrm{C}$ were considered to be febrile. Pregnancy was diagnosed by transrectal ultrasonography on days 34 and 60 after insemination.

\subsubsection{Experiment 2: intrauterine N. caninum inoculation of cows using contaminated semen with different numbers of tachyzoites}

The 37 cows were randomly allocated into four groups (a, b, c, and d) of 9, 10, 9, and 9 animals, respectively, and were kept isolated from other livestock in SERIDA facilities located in Villaviciosa (Asturias, Spain). Management, feeding, oestrus synchronization, and AI procedures were similar to those explained for heifers previously. Group a was inseminated with semen not contaminated with $N$. caninum tachyzoites and acted as a non-infected control group. Cows from groups b, c, and d were inseminated with semen contaminated with $10^{2}$, $5 \times 10^{3}$, and $5 \times 10^{5}$ live $N$. caninum NC-1 isolatetachyzoites, respectively. The experiment was conducted between October and December 2004. The cows were monitored daily for 63 days pi. Because all cows had previously shown diverse infertility problems pregnancies were not followed.

\subsection{Parasite inoculum}

Tachyzoites used to contaminate semen in both experiments were obtained from monkey kidney cell (MARC-145) monolayer cultures of the $N$. caninum NC-1 isolate. Briefly, cells were maintained in Dulbecco's modified Eagle medium supplemented with $10 \%$ foetal bovine serum, $15 \mathrm{mM} \mathrm{N}$-2-hydroxyethylpiperazine- $N^{\prime}$-2-ethane-sulfonic acid $(\mathrm{pH} 7.2), 2 \mathrm{mM}$ glutamine, $100 \mathrm{U} / \mathrm{ml}$ penicillin, $100 \mu \mathrm{g} / \mathrm{ml}$ streptomycin, and $250 \mathrm{ng} / \mathrm{ml}$ fungizone, and incubated $\left(37^{\circ} \mathrm{C}, 5 \%\right.$ $\mathrm{CO}_{2}$ ). Cells were passed twice a week. Tachyzoites were maintained by serial passage on MARC-145 monolayers at a 1:1 host-parasite ratio, and were harvested from monolayers after 4 days of culturing by scraping the parasite-infected cell monolayer using a sterile cell scraper. Cells were washed three times in sterile 0.3 M phosphate-buffered saline (PBS, $\mathrm{pH} 7.4$ ) and separated from host cell debris by passing the mixture through a 25-gauge needle after passage through a $5 \mu \mathrm{m}$ polycarbonate filter. Tachyzoites were counted in a haemocytometer and resuspended in PBS. For experiment 1 , the different tachyzoite doses $\left(10^{2}\right.$, $5 \times 10^{3}, 5 \times 10^{4}$, and $5 \times 10^{5}$ ) were diluted in $250 \mu \mathrm{l}$ of PBS and added to $250 \mu \mathrm{l}$ of semen and packed in $500 \mu \mathrm{l}$ AI straws, which were transported in an insulated box $\left(37^{\circ} \mathrm{C}\right)$ to the barn for use. Parasites were administered to heifers within $30 \mathrm{~min}$ of harvest from tissue culture. On day 0 , all of the 7, 8, 9, and 5 heifers in groups $\mathrm{B}, \mathrm{C}, \mathrm{D}$, and $\mathrm{E}$ were inseminated with $500 \mu \mathrm{l}$ of diluted semen containing $10^{2}, 5 \times 10^{3}$, $5 \times 10^{4}$, and $5 \times 10^{5}$ live tachyzoites of the $N$. caninum $\mathrm{NC}-1$ isolate, respectively. Each of the five heifers in group A were inseminated with $250 \mu$ l of tachyzoitefree semen plus $250 \mu \mathrm{l}$ of PBS. For experiment 2, the same procedure was followed, but all the cows from groups $\mathrm{b}, \mathrm{c}$, and $\mathrm{d}$ were inseminated with semen containing $10^{2}, 5 \times 10^{3}$, and $5 \times 10^{5}$ live tachyzoites of the $N$. caninum NC-1 isolate, respectively. Each of the nine control cows (group a) were inseminated with $250 \mu l$ of tachyzoite-free semen plus $250 \mu$ l of PBS.

\subsection{Samples and procedures}

Blood samples were collected by coccygeal venipuncture in EDTA, plain and heparinized tubes for DNA extraction, serological and IFN- $\gamma$ analysis, respectively. In experiment 1 , parasitaemia and serology in heifers from groups B, C, D, and E were analyzed before insemination, three times a week until day $35 \mathrm{pi}$, and thereafter twice a week until day 100 pi. The IFN- $\gamma$ analysis was performed once fortnightly in heifers. 
Control heifers (group A) were sampled once fortnightly. In experiment 2, parasitaemia and serum IgG response were analyzed in all cows (groups a, b, c, and d) before insemination and weekly until day 63 pi.

Serum samples were assayed for specific $\mathrm{IgG}$ antibodies using a crude antigen commercial kit (CIVTEST) following instructions as recommended by the manufacturer. Positive and negative controls were provided in the kit and test results were expressed as relative index $\times 100$ (RIPC) values. A RIPC value between 6 and 9 was considered inconclusive and above 9 was regarded as positive.

To assess IFN- $\gamma$ production, duplicate aliquots of heparinized blood $(900 \mu \mathrm{l})$ from each heifer were transferred into each of the three wells of 24-well tissue culture plates (Soria Greiner, Spain) and cultured with $100 \mu \mathrm{l}$ of PBS (unstimulated control), concanavalin A $(10 \mu \mathrm{g} / \mathrm{ml}$; Sigma) to ensure the ability of the cells to respond to stimulation and secrete IFN- $\gamma$, and with $N$. caninum NC-1 strain soluble antigen. Optimal antigen concentration $(1 \mu \mathrm{g} / \mathrm{ml})$, and remaining assay parameters were determined previously by checkerboard titration using blood from a strongly seropositive heifer (not shown). Cultures were incubated $\left(16 \mathrm{~h}, 37^{\circ} \mathrm{C}, 5 \%\right.$ $\left.\mathrm{CO}_{2}\right)$. Plates were centrifuged $(500 \times g, 10 \mathrm{~min})$, plasma was harvested from each well and frozen at $-20{ }^{\circ} \mathrm{C}$ until testing. Duplicate plasma samples were tested for IFN- $\gamma$ production by ELISA (Bovigam IFN- $\gamma$ kit, CSL, Australia) following the manufacturer's recommendations. Test results were expressed as optical density (OD) values. The cut-off value $(0.27)$ was established as the mean of seronegative heifers plus three times their standard deviation.

For parasitaemia studies, DNA was extracted from $500 \mu \mathrm{l}$ of EDTA-whole blood using a Genomic-Prep Blood DNA isolation kit (Amersham Biosciences Ltd., UK) following manufacturer's instructions. A previously described nested PCR procedure [13] on the internal transcribed spacer (ITS1) region of $N$. caninum was used to detect the presence of Neospora DNA in blood. In each amplification, DNA extraction and PCR control equivalent to $10^{2}$ tachyzoites, respectively, were employed as positive controls. To identify false positive results, negative control reactions (reactions without template or reactions with DNA of $N$. caninum-negative blood) were added to each set of PCRs.

\subsection{Data analysis}

Rectal temperature, serological data, and pregnancy rates were analysed using an independent two-sample $t$ test to compare infected and control groups. A $p$-value of less than 0.05 was taken to indicate that the values of the two treatments were not similar.

\section{Results}

Heifers and cows showed virtually no clinical symptoms after parasite inoculation via AI. In both experiments, there was no significant difference between the groups when rectal temperature was compared (not shown).

Parasitaemia and serum IgG antibody, and IFN- $\gamma$ values above the cut-off levels in inoculated heifers from experiment 1 are shown in Table 1 . Two of 7 $(28.6 \%)$ heifers in group B, 5 of $8(62.5 \%)$ heifers in group C and 8 of $9(88.9 \%)$ heifers in group D showed parasitaemia, specific serum IgG antibody and/or IFN- $\gamma$ responses. The five $(100 \%)$ heifers from group $\mathrm{E}$ showed specific serum IgG antibody and/or IFN- $\gamma$ responses. No parasitaemia, nor specific serum IgG antibody and IFN- $\gamma$ responses were detected in any heifers from group A (control group).

In experiment 2 , only 1 of $9(11.1 \%)$ cows in group $d$ showed a specific serum IgG antibody response. No parasitaemia or specific serum IgG antibody responses were detected in any cows from groups a (control group), b, and c.

\subsection{Detection of N. caninum DNA in blood}

In experiment $1, N$. caninum DNA was detected in 1 , 2 , and 3 heifers from groups $\mathrm{B}, \mathrm{C}$, and $\mathrm{D}$, respectively, between 9 and 23 days pi (Table 1). Parasitaemia was detected at day 19 pi in one heifer from groups B and C, respectively. In addition, one heifer from group $\mathrm{C}$ showed parasitaemia at 19 and 23 days pi. In group D, $N$. caninum DNA was detected in three heifers at 9, 12, and 23 days pi, respectively. No parasitaemia was detected in any of the five heifers in group E.

In experiment 2 , no $N$. caninum DNA was detected in any blood sample of inoculated cows.

\subsection{N. caninum-specific antibody responses}

In experiment 1 , specific serum IgG levels above cutoff value were detected in 1, 2, 3, and 4 heifers from groups B, C, D, and E, respectively (Table 1). In group $\mathrm{B}$, one heifer showed a specific serum IgG antibody level at 21 days pi. In group $\mathrm{C}$, two heifers showed transient specific serum IgG antibody responses between 28 and 69, and 42 and 72 days pi, respectively. In group $\mathrm{D}$, two heifers showed persistent specific serum IgG antibody responses from 30 and 47 to 100 
Table 1

Detection of $N$. caninum DNA in blood (P) and specific serum IgG antibody and IFN- $\gamma$ levels of 7, 8, 9, and 5 heifers experimentally infected with $10^{2}$ (group B), $5 \times 10^{3}$ (group C), $5 \times 10^{4}$ (group D), and $5 \times 10^{5}$ (group E) N. caninum tachyzoites of NC-1 isolate via contaminated semen, respectively

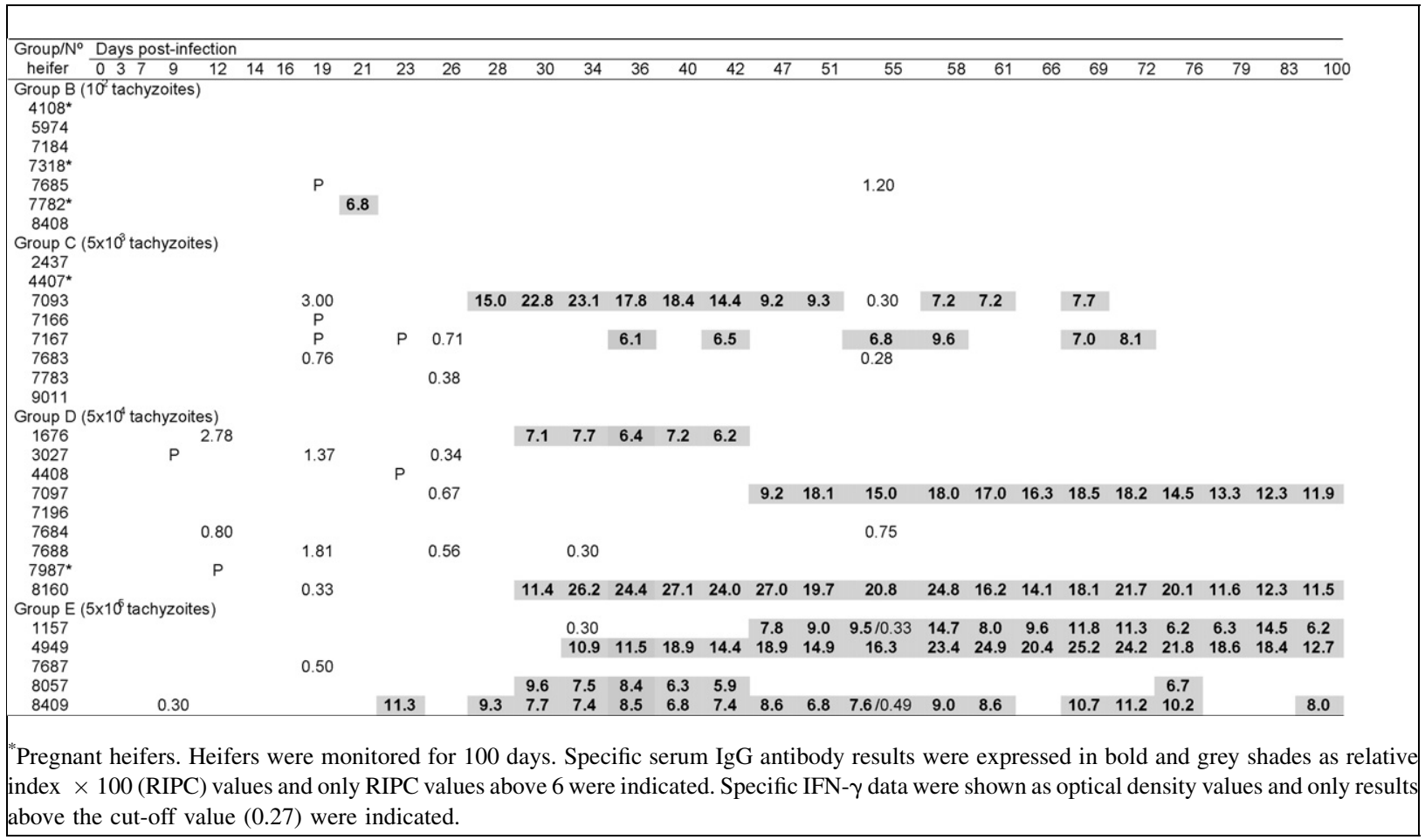

days pi, respectively. In addition, one heifer showed a transient specific serum IgG antibody response between 30 and 42 days pi. In group E, three heifers showed persistent specific serum IgG antibody responses from 23,34 , and 47 to 100 days pi, respectively. Other heifer showed specific serum IgG antibody levels between 30 and 76 days pi. Heifers seroconverted between 21 and 47 days pi. Serum IgG antibody levels of individual seroconverted heifers fluctuated over time and occasionally fell below the cut-off level in some animals (Table 1).

In experiment 2, only one cow inoculated with $5 \times 10^{5}$ tachyzoites (group d) showed RIPC values of 9.4, 18.9, and 18.1 at 42, 56, and 63 days after insemination, respectively.

\subsection{N. caninum-specific IFN- $\gamma$ responses in heifers}

Specific IFN- $\gamma$ levels above cut-off value were detected in 1, 4, 6, and 3 heifers from groups B, C, D, and $\mathrm{E}$, respectively, between 9 and 55 days pi (Table 1). In group B, a specific IFN- $\gamma$ level was detected in one heifer at 55 days pi. In group C, specific IFN- $\gamma$ levels were detected in four heifers between 19 and 55 days pi. In group $\mathrm{D}$, specific IFN- $\gamma$ levels were detected in six heifers between 12 and 55 days pi. In group E, specific IFN- $\gamma$ levels were detected in three heifers between 9 and 55 days pi.

\subsection{Pregnancy rates in heifers}

In experiment 1 , pregnancy was diagnosed by transrectal ultrasonography in 3 (7197, 7682, 7984), 3 (4108, 7318, 7782), 1 (4407), and 1 (7987) heifers of groups A, B, C, D, and E, respectively. Pregnancy rate in the control group $(60 \%)$ was significantly $(p<0.05)$ higher than those observed in inoculated heifers $(0-$ $42.9 \%$ ). In addition, pregnancy rates in inoculated heifers were higher when the tachyzoite dose decreased (B $42.9 \%$, C $12.5 \%$, D $11.1 \%$, and E 0\%). Pregnant heifers did not show seroconversion, although heifers 7782 and 7987 showed a RIPC value of 6.8 at 21 days pi and parasitaemia at 12 days pi, respectively (Table 1). All pregnant heifers, except for numbers 7197 and 4108, gave birth to one healthy calf, respectively. None of the calves showed specific antibodies to $N$. caninum when 
precolostral samples were analysed by ELISA (CIVTEST). Heifers 7197 and 4108 did not successfully complete gestation but no infectious origin was diagnosed.

\section{Discussion}

This study was carried out to investigate the potential of different $N$. caninum tachyzoite numbers to infect healthy heifers and cattle with reproductive problems (cows with confirmed infertility problems such as polycystic ovary and chronic endometritis) when administered in utero by AI via experimentallycontaminated semen. The infection was assessed by showing the presence of serum-specific antibodies to $N$. caninum in inoculated cattle. The specific IFN- $\gamma$ response and the presence of $N$. caninum DNA in their blood were also investigated.

Some heifers inoculated with doses equal to or higher than 5000 tachyzoites showed a measurable humoral immune response, but only some heifers inseminated with semen containing $5 \times 10^{4}$ and $5 \times 10^{5} \mathrm{~N}$. caninum tachyzoites, respectively, reacted with persistent seroconversion, indicating continuous exposure to parasite antigens. These results support a previous work where intrauterine inoculation via experimentally-contaminated semen with $10^{7} \mathrm{~N}$. caninum tachyzoites caused $N$. caninum infection in heifers [16]. However, only one cow inoculated with a high tachyzoite dose $\left(5 \times 10^{5}\right.$ tachyzoites $)$ showed a specific serological response.

Although the experiments were not performed under strict gnotobiotic conditions, we consider it unlikely that there was any other source of $N$. caninum infection in the seroconverted cattle other than the inoculation performed. The control heifers and cows did not show specific serological responses nor $N$. caninum DNA in blood over the entire experimental period and the animals of each experiment were housed in the same pen and were fed the same fodder as seroconverted cattle.

The inoculum used in our experiments, consisted of a crude cell culture harvest containing free $N$. caninum tachyzoites mixed with bovine semen. The tachyzoite doses were calculated to evaluate the threshold level at which infection is induced by the intrauterine route via experimentally-contaminated semen. On the basis of serological data, a dose-response effect was observed in inoculated heifers. The number of heifers showing a serum-specific antibody response increased when the number of tachyzoites inoculated was higher. Moreover, the persistency of serum IgG response was present mainly in seroconverted heifers inoculated with the higher tachyzoite doses. However, the magnitude of the immune responses was not correlated with the number of tachyzoites inoculated. It was concluded that only heifers inoculated with $5 \times 10^{4}$ or more tachyzoites showed a persistent specific antibody response to $N$. caninum. It seems that the intrauterine infection route could have an effect on the number of viable tachyzoites. Therefore, this effect would be even more important in the case of lower infectious doses.

Results obtained in inoculated cows showed that only one animal seroconverted and in this case a higher tachyzoite dose than in healthy cyclic heifers was needed. Two main causes could explain this low seroconversion rate obtained in older animals. First, the age differences between both experimentally-infected groups since it seems that cows could show some type of resistance to experimental seminal infection with $N$. caninum tachyzoites compared to heifers. Recently, Canada et al. [17] also failed to induce neosporosis in four cows artificially inseminated with semen in vitro contaminated with approximately $1 \times 10^{7}$ tachyzoites of the NC-1 strain. Although slightly different, a higher abortion risk has been observed in congenitally-infected heifers during their first gestation compared with first pregnancy of first and second lactation [18] and the proportion of congenitally-infected calves decreased with increasing parity of the dams $[19,20]$. Second, infertility problems associated with cows used in the present experiment, including chronic endometritis and irregular hormonal cycles should also be considered. These alterations may influence endometrial mucosa and thus, receptivity to $N$. caninum tachyzoites. No conclusions on a dose-response effect could be drawn because only one cow inoculated with the highest dose $\left(5 \times 10^{5}\right.$ tachyzoites) used showed persistent seroconversion.

The specific antibody response in persistently seroconverted heifers commenced between 28 and 47 days pi and antibody levels then increased and remained at a plateau, indicating active infection with ongoing antigenic stimulus obviously due to an active infection. This general pattern of $\mathrm{IgG}$ response was similar to those reported for heifers inoculated in utero by AI via semen contaminated with $10^{7}$ tachyzoites [16], and for calves $[9,21,22]$ and pregnant cows $[10,23]$ challenged with tachyzoites or oocysts. However, we made two interesting observations apparently irrespective of the number of tachyzoites inoculated. First, the magnitude of humoral immune response was not similar between seroconverted heifers [16]. Second, the rise in specific antibody levels following inoculation tended to start 
later than in other experimental infections with similar parasite numbers and using other inoculation routes $[10,22]$. These findings could reflect the course of the intrauterine route of infection where tachyzoites must resist the passage through the genital tract, reach and invade uterine mucosa (and possibly multiply) before systemic dissemination through the blood system.

Interestingly, four inoculated heifers showed transient specific immune responses, which oscillated between 2 and 6 weeks. We have no clear explanation why these heifers became seronegative after serumspecific antibody detection, especially one heifer which showed a peak RIPC value of $23 \%$ at day 30 pi. A transient serologic response assessed by ELISA in dairy cattle that did not develop an infection have already been described by Hietala and Thurmond [24]. These authors interpreted these responses as a stimulation of specific antibody following postnatal exposure, without subsequent infection. Recently, Canada et al. [17] reported a transient low-titre serological response by means of a direct agglutination test (DAT) in one cow inseminated with semen contaminated with approximately $1 \times 10^{7} \mathrm{~N}$. caninum tachyzoites and suggested a stimulation of the immune system by the tachyzoites placed in uterus, rather than induction of infection. However, those four cows were not sacrificed and it was not possible to isolate the parasite or detect its DNA in tissues such as brain and genital tract. The fluctuations of serum antibody titres, widely reported in cattle naturally [25] and experimentally ([22], particularly in animals infected with a low dose) infected with $N$. caninum, would also be implicated. Recently, a report concluded that $N$. caninum antibody titres may drop or convert to seronegative status in chronically infected cows by the time of parturition [26] and highlighted the difficulty of interpreting results of serological tests for neosporosis, especially when the antibody response is weak and a low or negative result does not necessarily mean that an animal is not infected. If the infection of these heifers were confirmed, the infection threshold level of the intrauterine route would be established in approximately 5000 tachyzoites.

We determined the parasite load in semen from five naturally-infected seropositive bulls and found a range of 1-10 tachyzoites (mean 2.5) per $\mathrm{ml}$ of semen, equivalent to an ejaculate containing approximately 100 parasites [15]. Recently, eight bulls were experimentally infected with $10^{8}$ tachyzoites of $N$. caninum and showed a mean parasite load of six tachyzoites per $\mathrm{ml}$ of semen (with a peak number of 15 parasites/ml in some animals), associated with the chronic stage of infection [27]. The current study suggests a threshold level of between 5000 and 50,000 tachyzoites for venereal route. This number seems very different to the parasite load described in naturally and experimentally infected bulls. However, the repeated services of ejaculates containing 100-150 tachyzoites, which is common in beef cattle breeds under extensive management [28], possibly attaining the minimum number of tachyzoites required to induce infection. In addition, infection could be facilitated by parasites being enclosed in host cells such as mononuclear phagocytic cells. Under these conditions, tachyzoites could better to resist passage through the genital tract than free tachyzoites, thereby retaining infectivity when reaching the uterine mucosa. Our observations was that most $N$. caninum DNA is found in the cell fraction, and virtually no specific DNA is present in seminal fluid supports this hypothesis $[13,15]$.

Parasitaemia was detected in some heifers between 9 and 23 days pi. This seems to correlate with the size of the infectious dose, but surprisingly no specific DNA was detected in any heifer infected with $5 \times 10^{5}$ tachyzoites. On the other hand, the presence of specific DNA in blood was not associated with a specific antibody response later, except in one heifer showing a transient IgG response. Several authors have pointed out the difficulty of detecting $N$. caninum in tissues and fluids such as blood in adult cattle, whether naturally or experimentally infected, because of the low number of parasites and their irregular distribution $[9,10,15]$. The detection of Neospora DNA in blood would represent evidence of infection since the blood seems to provide the transport medium for tachyzoites between body tissues. The lack of a serum-specific antibody response after parasitaemia could be explained because the detection of specific DNA in blood does not necessarily imply the presence of infectious parasitic stages. However, De Marez et al. [9] reported one infected calf showing specific DNA in brain but without a demonstrable serum antibody response against $N$. caninum, indicating a possible heterogeneity in antibody response in cattle.

Our results suggest that $N$. caninum infection via semen could affect early pregnancy in heifers. Control heifers showed a pregnancy rate $(60 \%)$ consistent with that observed in other heifers of the same breed [29]. In contrast, the overall pregnancy rate (17.2\%) of inoculated heifers was notably lower and pregnancy rates decreased as infectious doses increased (0-42.9\%).

Since all heifers were similar in genetics and reproductive status and were managed in a similar way (AI procedures, nutrition, hygiene and pen conditions), the only difference between groups was the presence of different numbers of $N$. caninum tachyzoites 
in semen. The low pregnancy rate in the inoculated heifers could be due to infection and eventual death of the embryos. However, in a previous work we failed to detect $N$. caninum DNA in a recovered embryo from a heifer inoculated with $10^{7}$ tachyzoites via semen [16]. This finding was in line with in vitro studies, which have shown that preimplantation stage bovine embryos are protected by the zona pellucida against Neospora invasion [30]. In the mentioned study, we hypothesised that in the early stages of pregnancy the tachyzoites included in semen may damage the uterus mucosa on the basis of Neospora DNA detection in the uterine horn of some infected heifers. The inflammatory response to tachyzoite cell invasion could prevent implantation and/ or facilitate embryo expulsion. It is shown that the inflammatory changes in endometrium of heifers infected with Tritrichomonas foetus likely influence conception and pregnancy [31]. Unfortunately, in the current study heifers were not sacrificed and it is not possible to draw conclusions related to the presence of the parasite in genital tract tissues.

There are conflicting reports in the literature concerning foetal loss in early pregnancy caused by $N$. caninum infection. Björkman et al. [32] found no significant difference between the number of inseminations per confirmed pregnancy in relation to serological status to $N$. caninum, and López-Gatius et al. [33] reported that chronic neosporosis, determined by means of a prospective analysis through maternal serology, fails to affect the early foetal period. However, two recent studies $[34,35]$ report that $N$. caninum infected cows required more inseminations per confirmed pregnancy than their seronegative herd mates. The greater number of services required to conceive may indicate that early foetal loss could be occurring.

This study demonstrates that intrauterine infection via contaminated semen using $5 \times 10^{4}$ and $5 \times 10^{5}$ tachyzoites results in persistent specific antibody response in some heifers. The number of heifers showing specific serum IgG antibodies to $N$. caninum following experimental infection appears to correlate with the number of tachyzoites used. However, a similar experiment carried out with infertile cows showed that only one animal seroconverted when $5 \times 10^{5}$ tachyzoites were placed in the uterus. The lower pregnancy rate observed in inoculated heifers when compared to the control group, suggests that $N$. caninum is probably the cause of early foetal loss. However, although our work provides evidence that horizontal transmission via contaminated semen is feasible in bovine neosporosis, further studies are underway to assess its role in the spread of bovine neosporosis under natural conditions.

\section{Acknowledgements}

We are grateful to ASEAVA (Asociación de Criadores de Ganado Vacuno Selecto de la Raza Asturiana de los Valles) for providing bovine semen and Vanesa Navarro and caretakers of "Finca La Mata", specially to José Luis Antón, for technical assistance. Funding for this work was provided by a research grant from the Spanish government (Pr95-0780.OP). Ignacio Ferre was financed by the Ramón y Cajal Spanish Scientific Programme. This work was also part of the EU research collaboration COST-854.

\section{References}

[1] Dubey JP. Review of Neospora caninum and neosporosis in animals. Korean J Parasitol 2003;41:1-16.

[2] Dubey JP. Neosporosis in cattle. J Parasitol 2003;89:S42-56.

[3] McAllister MM, Dubey JP, Lindsay DS, Jolley WR, Wills RA, McGuire AM. Dogs are definitive hosts of Neospora caninum. Int J Parasitol 1998;28:1473-8.

[4] Gondim LFP, McAllister MM, Pitt WC, Zemlicka DE. Coyotes (Canis latrans) are definitive hosts of Neospora caninum. Int J Parasitol 2004;34:159-61.

[5] Paré J, Thurmond MC, Hietala SK. Congenital Neospora caninum infection in dairy cattle and associated calfhood mortality. Can J Vet Res 1996;60:133-9.

[6] Davison HC, Otter A, Trees AJ. Estimation of vertical and horizontal transmission parameters of Neospora caninum infections in dairy cattle. Int J Parasitol 1999;29:1683-9.

[7] Uggla A, Stenlund S, Holmdahl OJM, Jakubek E-B, Thebo P, Kindahl H, et al. Oral Neospora caninum inoculation of neonatal calves. Int J Parasitol 1998;28:1467-72.

[8] Dijkstra Th, Barkema HW, Eysker M, Wouda W. Evidence of post-natal transmission of Neospora caninum in Dutch dairy herds. Int J Parasitol 2001;31:209-15.

[9] De-Marez T, Liddell S, Dubey JP, Jenkins MC, Gasbarre L. Oral infection of calves with Neospora caninum oocysts from dogs: humoral and cellular immune responses. Int J Parasitol 1999;29: 1647-57.

[10] Trees AJ, McAllister MM, Guy CS, McGarry JW, Smith RF, Williams DJL. Neospora caninum: oocyst challenge of pregnant cows. Vet Parasitol 2002;109:147-54.

[11] Gondim LM, Gao L, McAllister MM. Improved production of Neospora caninum oocysts, cyclical oral transmission between dogs and cattle, and in vitro isolation from oocysts. J Parasitol 2002;88:1159-63.

[12] Gondim LFP, McAllister MM, Mateus-Pinilla NE, Pitt WC, Mech LD, Nelson ME. Transmission of Neospora caninum between wild and domestic animals. J Parasitol 2004;90: 1361-5.

[13] Ortega-Mora LM, Ferre I, del-Pozo I, Caetano-da-Silva A, Collantes-Fernández E, Regidor-Cerrillo J, et al. Detection of Neospora caninum in semen of bulls. Vet Parasitol 2003;117: 301-8.

[14] Caetano-da-Silva A, Ferre I, Collantes-Fernández E, Navarro V, Aduriz G, Ugarte-Garagalza C, et al. Occasional detection of Neospora caninum DNA in frozen extended semen from naturally infected bulls. Theriogenology 2004;62:1329-36. 
[15] Ferre I, Aduriz G, del-Pozo I, Regidor-Cerrillo J, Atxaerandio R, Collantes-Fernández E, et al. Detection of Neospora caninum in the semen and blood of naturally infected bulls. Theriogenology 2005;63:1504-18.

[16] Serrano E, Ferre I, Osoro K, Aduriz G, Mateos-Sanz A, Martínez A, et al. Intrauterine Neospora caninum inoculation of heifers. Vet Parasitol 2006;135:197-203.

[17] Canada N, Meireles CS, Ferreira P, Correia-da-Costa JM, Rocha A. Artificial insemination of cows with semen in vitro contaminated with Neospora caninum tachyzoites failed to induce neosporosis. Vet Parasitol 2006;139:109-14.

[18] Thurmond MC, Hietala SK. Effect of congenitally acquired Neospora caninum infection on risk of abortion and subsequent abortions in dairy cattle. Am J Vet Res 1997;58:1381-5.

[19] Dijkstra T, Barkema HW, Eysker M, Beiboer ML, Wouda W. Evaluation of a single serological screening of dairy herds for Neospora caninum antibodies. Vet Parasitol 2003;110:161-9.

[20] Romero JJ, Perez E, Dolz G, Frankena K. Factors associated with Neospora caninum serostatus in cattle of 20 specialized Costa Rican dairy herds. Prev Vet Med 2002;53:263-73.

[21] Williams DJL, Guy CS, McGarry JW, Guy F, Tasker L, Smith RF, et al. Neospora caninum-associated abortion in cattle: the time of experimentally-induced parasitaemia during gestation determines foetal survival. Parasitology 2000;121:347-58.

[22] Maley SW, Buxton D, Thomson KM, Schriefer ES, Innes EA. Serological analysis of calves experimentally infected with Neospora caninum: a 1-year study. Vet Parasitol 2001;96:1-9.

[23] Andrianarivo AG, Barr BC, Anderson ML, Rowe JD, Packham $\mathrm{AE}, \mathrm{Sverlow} \mathrm{KW}$, et al. Immune responses in pregnant cattle and bovine fetuses following experimental infection with Neospora caninum. Parasitol Res 2001;87:817-25.

[24] Hietala SK, Thurmond MC. Postnatal Neospora caninum transmission and transient serologic responses in two dairies. Int $\mathrm{J}$ Parasitol 1999;29:1669-76.

[25] Pereira-Bueno J, Quintanilla-Gozalo A, Seijas-Carballedo A, Costas E, Ortega-Mora LM. Observational studies in Neospora caninum infected dairy cattle: pattern of transmission and agerelated antibody fluctuations. Int J Parasitol 2000;30:906-9.
[26] Kyaw T, Suwimonteerabutr J, Virakul P, Lohachit C, Kalpravidh W. Seronegative conversion in four Neospora caninum-infected cows, with a low rate of transplacental transmission. Vet Parasitol 2005;131:145-50.

[27] Ferre I, Martínez A, Serrano E, Osoro K, Mateos-Sanz A, Tamargo C, et al. Detection of Neospora caninum in the semen and blood during acute and chronic experimental neosporosis in bulls. In: Abstracts of COSTAction 854 "Protozoal reproduction losses in farm ruminants" Annual Meeting. Wiadomosci Parazytologiczne 2005;51, supplement:p. 15-8.

[28] Moore DP, Draghi MG, Campero CM, Cetra B, Odeon AC, Alcaraz E, et al. Serological evidence of Neospora caninum infections in beef bulls in six counties of the Corrientes province, Argentina. Vet Parasitol 2003;114:247-52.

[29] Ormazabal JJ, Osoro K, Martínez A. Efecto de los niveles de crecimiento y la presencia del toro en la edad a la pubertad de las novillas de raza Asturiana de los Valles. Investigación Agraria: Producción y Sanidad Animal 1996;11:201-14.

[30] Bielanski A, Robinson J, Phipps-Todd B. Effect of Neospora caninum on in vitro development of preimplantation stage bovine embryos and adherence to the zona pellucida. Vet Rec 2002;150: 316-8.

[31] Anderson ML, BonDurant RH, Corbeil RR, Corbeil LB. Immune and inflammatory responses to reproductive tract infection with Tritrichomonas foetus in immunized and control heifers. J Parasitol 1996;82:594-600.

[32] Björkman C, Johansson O, Stenlund S, Holmdahl OJM, Uggla A. Neospora species infection in a herd of dairy cattle. J Am Vet Med Assoc 1996;208:1441-4.

[33] López-Gatius F, Pabón M, Almería S. Neospora caninum infection does not affect early pregnancy in dairy cattle. Theriogenology 2004;62:606-13.

[34] Muñoz-Zanzi CA, Thurmond MC, Hietala SK. Effect of bovine viral diarrhea virus infection on fertility of dairy heifers. Theriogenology 2004;61:1085-99.

[35] Hall CA, Reichel MP, Ellis JT. Neospora abortions in dairy cattle: diagnosis, mode of transmission and control. Vet Parasitol 2005;128:231-41. 